\title{
Performance Characteristics of a New Rapid Immunochromatographic Test for the Detection of Antibodies to Human Immunodeficiency Virus (HIV) Types 1 and 2
}

\author{
H. Syed Iqbal, P. Balakrishnan, ${ }^{*}$ K.G. Murugavel, and Solomon Suniti \\ YRG Centre for AIDS Research and Education (YRG CARE), Voluntary Health Services Hospital Campus, \\ Chennai, India
}

\begin{abstract}
Diagnostic kits for the detection of human immunodeficiency virus (HIV) antibodies have reached an unprecedented number. But choice of an ideal, cost-effective, and rapid test for HIV infection is of immense value for use in developing countries like India, where resources are limited. In this study we have evaluated the performance characteristics of the rapid immunochromatographic HIV test kit First Response HIV 1-2.O. First, the laboratory archived 450 characterized plasma/serum specimens, which were tested on First Response HIV 1-2.O. Second, a total of 134 consecutive voluntary counseling and testing (VCT) specimens were also tested and positive specimens were further confirmed with HIV TRI-DOT. All these VCT specimens were cross-checked with HIV double-enzymelinked immunosorbent assay (ELISA) (Murex and Vironostika), and the results were matched. The sensitivity, specificity,
\end{abstract}

positive predictive value (PPV), negative predictive value (NPV), and efficiency of First Response HIV 1-2.O with the 450 characterized specimens was $100 \%$ for HIV-1 with reference assay. The results in the VCT algorithm were correlating with double-ELISA. In the HIV-2 analysis, five HIV-2-positive specimens in First Response HIV 1-2.O were found to be HIV2-indeterminate on Western blot. HIV TRIDOT was unable to pick up two HIV-2 Western blot-positive specimens. First Response HIV 1-2.O has several advantages: low-cost (U.S. $\$ 0.70$ ); only $10 \mu \mathrm{L}$ of specimen; involves only two steps; room temperature storage; ability to differentiate HIV-1 and 2; and use of whole blood specimen. Hence this test kit could be suitable for initial screening in the HIV testing algorithm in resource-limited settings. J. Clin. Lab. Anal. 22:178-185, 2008. (c) 2008 Wiley-Liss, Inc.

Key words: HIV rapid assay; HIV-2 western blot; HIV testing algorithm

\section{INTRODUCTION}

Human immunodeficiency virus (HIV) infection in India was first detected in 1986 among female sex workers in Chennai (1). Today, with an estimated 2.5 million HIV infections (2), among adults the HIV prevalence is $0.36 \%$. India is home to the third largest population of people living with HIV disease. The epidemic of HIV/acquired immunodeficiency syndrome (AIDS) in India is distributed between the urban and rural populations, mainly in the southern and western states of the country (3).

Conventional enzyme-linked immunosorbent assay (ELISA) testing for HIV is an efficient way to screen large numbers of specimens at one time (4). However, the disadvantages of the ELISA are the need for welltrained technical manpower, appropriate equipment, and batch testing $(4,5,6)$. Many clinics or point-of-care facilities in India are poorly equipped and often lack diagnostic capabilities (7). But initial results are often not available immediately. This obstructs effective and timely management of patients infected with HIV $(8,9,10)$. This limitation has led to the development of rapid HIV test kits, which do not require laboratory infrastructure or highly skilled personnel, and can provide results in less than $30 \mathrm{~min}$ (11). The assays are needed to be simple, rapid, and should be able to give

\footnotetext{
*Correspondence to: Dr. P. Balakrishnan. Ph.D., YRG Centre for AIDS Research and Education, Voluntary Health Services campus, IT Corridor, Taramani, Chennai - 600 113, India. E-mail: bala@yrgcare.org

Received 19 November 2007; Accepted 7 February 2008

DOI $10.1002 /$ jcla. 20238

Published online in Wiley InterScience (www.interscience.wiley.com).
} 
accurate results. Additionally, the uses of rapid test kits play a major role for appropriate and timely counseling for the voluntary counseling and testing (VCT) clients, since many clients will not come back to get results when they were called after some days due to transportation hardships $(9,10,12)$. Also specimens are sent miles away from the point-of-care facility for testing or even to reference laboratories outside the country.

The present study was aimed to evaluate the performance characteristics of the rapid HIV test kit First Response HIV card test 1-2.O (PMC Medical India Pvt. Ltd, Daman, India), which works with the principle of immunochromatography and the antigens gp41, p24 including subtype $\mathrm{O}$, which also differentiates HIV-1 and 2 (with the gp36 antigen).

\section{MATERIALS AND METHODS}

This study was carried out at the Y.R. Gaitonde Centre for AIDS Research and Education (YRG CARE), Chennai, India. It is one of the leading referral center for VCT in South India, which to date has counseled more than 20,000 clients; the HIV prevalence in VCT clients is about $65 \%$ (13).

\section{Characterized Specimens}

The following four sets of laboratory-archived characterized specimens were subjected to First Response HIV card test 1-2.O and the results were compared. 1) A total of 216 HIV seropositive specimens and 2) 134 HIV seronegative specimens were screened by HIV doubleELISA (HIV-1.2.0; Murex Biotech Limited, Dartford, $\mathrm{UK}$ and Vironostika HIV Uni-Form II Ag/Ab; Biomerieux, Boxtel, The Netherlands); these specimens were also confirmed with HIV-1 Western blot (Genetic SystemsTM HIV-1 Western Blot; Bio-Rad Laboratories, Redmond, WA). Western blot was considered positive for HIV-1 if any two of the following viral proteins were present: p24, gp41, and gp120/160. 3) A total of 100 seronegative specimens screened by U.S. Food and Drug Administration (FDA)-approved ELISA (Genetic SystemsTM HIV-1/2 PLUS O EIA) and 4) proficiency testing panel specimens $(\mathrm{n}=30$, which include HIV-2-seropositive specimens) from College of American Pathologists (CAP, Chicago, IL) were used in this analysis. The results of the proficiency testing panel were compared with the proficiency testing panel peer group evaluation reports.

\section{Assay Methodology}

Briefly, $10 \mu \mathrm{L}$ of the serum/plasma is added to the specified well in the membrane test assembly followed by one drop of assay diluent from the reagent dropper bottle. The test is read at an outer limit of 5 to $15 \mathrm{~min}$. A colored band should appear in the region marked as "C" (control) in order for the test to be valid. In addition, for positive specimens, a band should be present in the result window marked " 1 " (for HIV-1) or "2" (for HIV-2) or both (dual infection). Tests were performed by highly-trained technical personnel. All tests were performed according to the manufacturer's instructions.

\section{VCT Specimens}

A new serial HIV testing algorithm was launched in our center in October, 2006 (Fig. 1), which includes First Response HIV card test 1-2.O. The other kit being used in this algorithm is HIV TRI-DOT (BIOMED Industries, Parwanoo, H.P. India), which has an immunofiltration test principle using HIV-1 gp41, the C terminal of gp120, and gp36, representing the immunodominant regions of the HIV-1 and HIV-2 envelope gene structure, respectively. Hence our algorithm used two assays with different antigenic bases. Here, the specimens were tested with First Response HIV card test 12.O. Specimens found negative were reported as negative. Specimens found positive for any HIV antibody were subjected to HIV TRI-DOT. If the specimen was found positive for HIV antibodies, it was reported as positive. If the specimen was negative (discordant), both the assays were repeated; if the specimen was positive in both assays, it was reported as positive and if the specimen was negative in both assays, it was reported as negative. If the specimen was positive in one assay again, it was reported as indeterminate and the patient was advised to repeat HIV screening after a month. When the new specimens were tested after a month and if the specimen was positive in both assays, it was reported as positive and if the specimen is negative in both assays, it was reported as negative. If the specimen was positive in one assay again, the patient was advised to go for Western blot. A total of 134 consecutive VCT specimens were included in the analysis. All these specimens were cross-checked with HIV double-ELISA (HIV-1.2.0; Murex Biotech Limited, Dartford, UK and Vironostika HIV Uni-Form II $\mathrm{Ag} / \mathrm{Ab}$; Biomerieux, Boxtel, The Netherlands), and the results were matched.

Specimens found positive for HIV-2 in this study were subjected to HIV TRI-DOT, BIOMED Industries rapid assay and also confirmed with HIV-1 (Genetic SystemsTM HIV-1 Western Blot, Bio-Rad Laboratories) and HIV-2 (NEW LAB BLOT II; Bio-Rad Laboratories, Marnes-la-Coquette, France) Western Blot assays. A specimen was considered HIV-2 Western blot-positive if one band found from each structural 


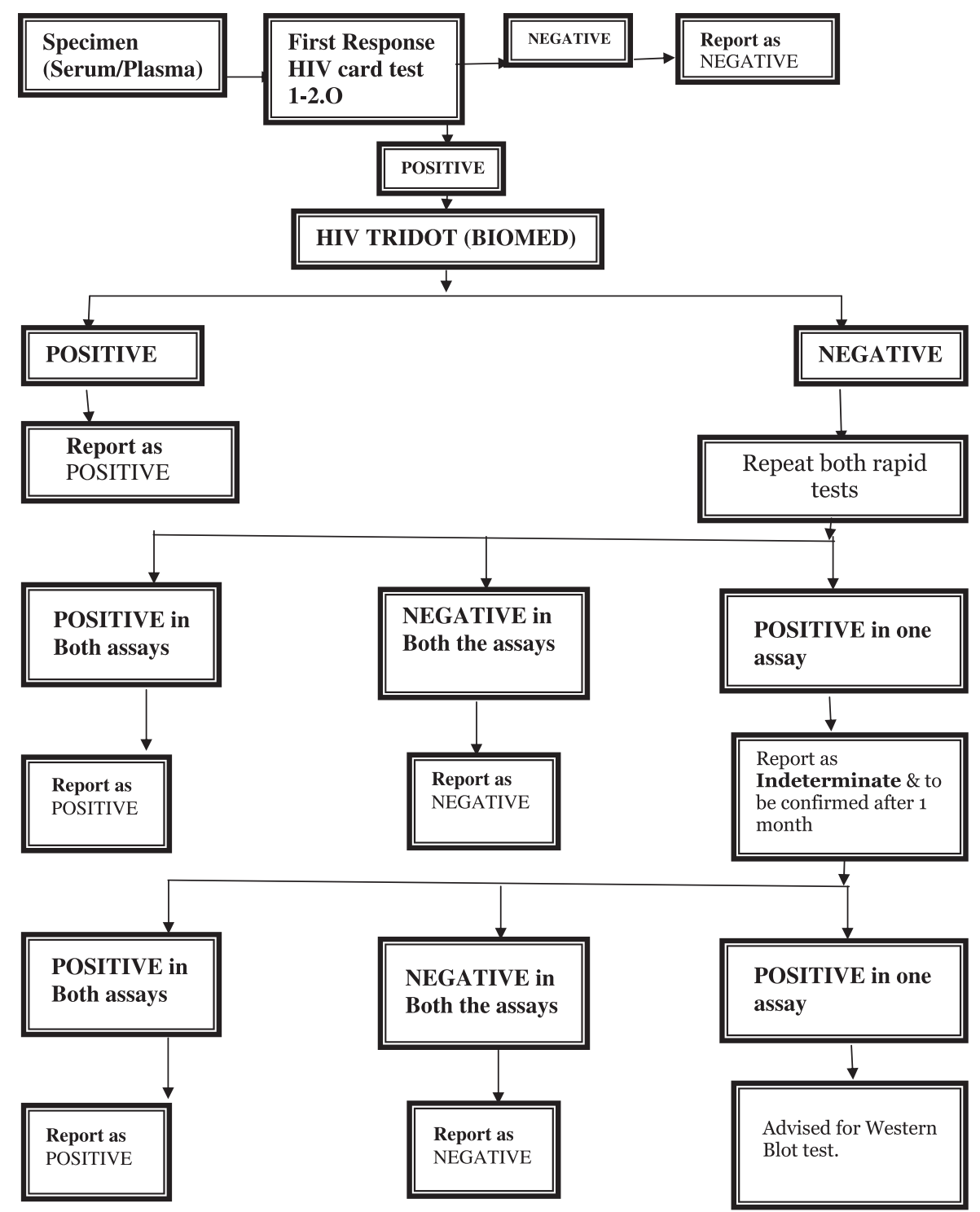

Fig. 1. HIV testing algorithm at YRG Center for AIDS Research and education.

protein was present; i.e., ENV + GAG + POL. A specimen was tested 10 times by two different technicians independently to check inter- and intrapersonal reproducibility.

\section{Statistical Analysis}

The performance characteristics were determined. The following formulas were used to calculate test indices (14):

$$
\begin{aligned}
& \text { sensitivity }=[\mathrm{TP} /(\mathrm{TP}+\mathrm{FN})] \times 100 \\
& \text { specificity }=[\mathrm{TN} /(\mathrm{TN}+\mathrm{FP})] \times 100 \\
& \text { positive predictive value }(\mathrm{PPV})=[\mathrm{TP} /(\mathrm{TP}+\mathrm{FP})]+100 \\
& \text { negative predictive value }(\mathrm{NPV})=[\mathrm{TN} /(\mathrm{TN}+\mathrm{FN})] \times 100 \\
& \text { efficiency }=[(\mathrm{TP}+\mathrm{TN}) /(\mathrm{TP}+\mathrm{FN}+\mathrm{TN}+\mathrm{FP})] \times 100,
\end{aligned}
$$

where TP $=$ number of true positives, $\mathrm{TN}=$ number of true negatives, $\mathrm{FN}=$ number of false negatives, and $\mathrm{FP}=$ number of false positives).

\section{RESULTS}

\section{Characterized Specimens}

The results with characterized specimens are summarized in Table 1. The sensitivity, specificity, PPV, NPV, and efficiency of the First Response HIV card test 1-2.O with 450 specimens was $100 \%$ for HIV-1. The First Response HIV card test 1-2.O has shown excellent performance characteristics; there are no discrepancies found when compared to the gold standard assay. Specimens found positive for HIV-2 were analyzed separately (Table 2). All the specimens from the 
TABLE 1. Performance characteristic of First Response HIV 1-2.O compared with gold standard assay

\begin{tabular}{lccc}
\hline $\begin{array}{l}\text { First response } \\
\text { HIV 1-2.O }(\mathrm{n}=450)\end{array}$ & $\begin{array}{c}\text { Positive by HIV double-ELISA } \\
\text { and Western blot }\end{array}$ & $\begin{array}{c}\text { Negative by HIV double-ELISA } \\
\text { and Western blot }\end{array}$ & $\begin{array}{c}\text { Negative by Genetic } \\
\text { Systems ELISA }\end{array}$ \\
\hline HIV-positive & 216 & 0 & 0 \\
HIV-negative & 0 & 134 & 100 \\
\hline
\end{tabular}

TABLE 2. Comparative results of HIV rapid assay with HIV Western Blot

\begin{tabular}{|c|c|c|c|c|c|c|c|c|}
\hline \multirow{2}{*}{$\begin{array}{l}\text { Specimen } \\
\text { number }\end{array}$} & \multicolumn{2}{|c|}{$\begin{array}{l}\text { First } \\
\text { Response } \\
\text { HIV card } \\
\text { test } 1-2 . \mathrm{O}\end{array}$} & \multicolumn{2}{|c|}{$\begin{array}{l}\text { TRI-DOT } \\
\text { BIOMED }\end{array}$} & \multicolumn{2}{|l|}{ HIV-1 Western blot } & \multicolumn{2}{|c|}{ HIV-2 Western blot } \\
\hline & HIV-1 & HIV-2 & HIV-1 & HIV-2 & Bands & Result & Bands & Result \\
\hline 1 & POS & POS & POS & POS & $\begin{array}{l}\text { gp160, gp120, p65, p55, } \\
\text { p51, gp41, p40, p31, p24, p18 }\end{array}$ & Positive & $\begin{array}{l}\text { gp140, gp105/125, p68, p56, } \\
\text { gp36, p34, p26, p16 }\end{array}$ & Positive \\
\hline 2 & POS & POS & POS & POS & $\begin{array}{l}\text { gp160, gp120, p } 65, \mathrm{p} 55, \\
\text { p51, gp41, p40, p31, p24, p18 }\end{array}$ & Positive & $\begin{array}{l}\text { gp140, gp105/125, p68, p56, } \\
\text { gp36, p34, p26, p16 }\end{array}$ & Positive \\
\hline 3 & POS & POS & POS & POS & $\begin{array}{l}\text { gp160, gp120, p65, p55, } \\
\text { p51, gp41, p40, p31, p24 }\end{array}$ & Positive & $\begin{array}{l}\text { gp140, gp105/125, p68, p56, } \\
\text { gp36, p34, p26, p16 }\end{array}$ & Positive \\
\hline 4 & POS & POS & POS & POS & $\begin{array}{l}\text { gp160, gp120, p65, p55, } \\
\text { p51, gp41, p40, p31, p24, p18 }\end{array}$ & Positive & $\begin{array}{l}\text { gp140, gp105/125, p68, p56, } \\
\text { gp36, p34, p26 }\end{array}$ & Positive \\
\hline 5 & POS & POS & POS & POS & $\begin{array}{l}\text { gp160, gp120, p65, p55, } \\
\text { p51, gp41, p40,p31, p24 }\end{array}$ & Positive & $\begin{array}{l}\text { gp140, gp } 105 / 125, \mathrm{p} 68 \\
\text { gp } 36, \mathrm{p} 34, \mathrm{p} 26\end{array}$ & Positive \\
\hline 6 & POS & POS & POS & POS & $\begin{array}{l}\text { gp160, gp120, p65, p55, } \\
\text { p51, gp41, p40, p31, p24, p18 }\end{array}$ & Positive & $\begin{array}{l}\text { gp } 140, \text { gp } 105 / 125, \mathrm{p} 68 \\
\text { gp } 36, \mathrm{p} 34, \mathrm{p} 26\end{array}$ & Positive \\
\hline 7 & POS & POS & POS & POS & $\begin{array}{l}\text { gp160, gp120, p65, p55, } \\
\text { p51, gp41, p40, p31, p24, p18 }\end{array}$ & Positive & $\begin{array}{l}\text { gp } 140, \text { gp } 105 / 125 \\
\text { p56, p34, p26 }\end{array}$ & Positive \\
\hline 8 & NEG & POS & NEG & POS & No bands & Negative & $\begin{array}{l}\text { gp140, gp105/125, p68, p56, } \\
\text { gp36, p34, p26, p16 }\end{array}$ & Positive \\
\hline 9 & NEG & POS & NEG & POS & gp160 & Indeterminate & $\begin{array}{l}\text { gp140, gp105/125, p68, p56, } \\
\text { gp36, p34 }\end{array}$ & Positive \\
\hline 10 & POS & POS & POS & NEG & $\begin{array}{l}\text { gp160, gp120, p65, p55, } \\
\text { p51, gp41, p40, p31, p24 }\end{array}$ & Positive & gp105/125, p68, p34, p26 & Positive \\
\hline 11 & POS & POS & POS & NEG & $\begin{array}{l}\text { gp160, gp120, p65, p55, } \\
\text { p51, gp41, p40, p31, p24 }\end{array}$ & Positive & gp105/125, p68, p56, p26, p16 & Positive \\
\hline 12 & POS & POS & NEG & POS & gp160, p31 & Indeterminate & $\begin{array}{l}\text { gp140, gp105/125, p68, p56, } \\
\text { gp36, p34, p26, p16 }\end{array}$ & Positive \\
\hline 13 & POS & POS & POS & NEG & $\begin{array}{l}\text { gp } 160, \text { gp } 120, \mathrm{p} 65, \mathrm{p} 55, \\
\mathrm{p} 51, \mathrm{gp} 41, \mathrm{p} 40, \mathrm{p} 31, \mathrm{p} 24, \mathrm{p} 18\end{array}$ & Positive & gp $105 / 125, \mathrm{p} 26$ & Indeterminate \\
\hline 14 & POS & POS & POS & NEG & $\begin{array}{l}\text { gp } 160, \text { gp } 120, p 65, \mathrm{p} 55 \\
\text { p51, gp } 41, \mathrm{p} 40, \mathrm{p} 31, \mathrm{p} 24, \mathrm{p} 18\end{array}$ & Positive & gp $105 / 125$, p26 & Indeterminate \\
\hline 15 & POS & POS & POS & NEG & $\begin{array}{l}\text { gp160, gp120, p65, p55, } \\
\text { p51, gp } 41, \text { p } 40, \text { p31, p24 }\end{array}$ & Positive & p26 & Indeterminate \\
\hline 16 & POS & POS & POS & NEG & $\begin{array}{l}\text { gp160, gp120, p65, p } 55, \\
\text { p51, gp41, p40, p31, p24, p18 }\end{array}$ & Positive & p26 & Indeterminate \\
\hline 17 & POS & POS & POS & NEG & $\begin{array}{l}\text { gp } 160, \text { gp } 120, \mathrm{p} 65, \mathrm{p} 55, \\
\text { p51, gp41, p40,p31, p24, p18 }\end{array}$ & Positive & p26 & Indeterminate \\
\hline
\end{tabular}

proficiency testing panel were correctly identified with First Response HIV card test 1-2.O; there were 11 HIV1 seropositive, 17 HIV seronegative, and a couple of HIV-1 and 2 dual infected specimens were identified. There were no discrepancies found in the proficiency testing panel specimen results, when compared with peer group evaluation reports.

\section{VCT Specimens}

The results obtained from our center's new HIV testing algorithm are shown in Table 3 . All the positive and negative results were correlated with HIV doubleELISA. However, there were discrepancies found between the assays in HIV-2 results. Since HIV 
TABLE 3. Comparative results of HIV testing algorithm with HIV double-ELISA

\begin{tabular}{|c|c|c|c|c|c|c|c|c|}
\hline \multirow{2}{*}{$\begin{array}{l}\text { HIV double-ELISA } \\
\text { (total } n=134 \text { ) }\end{array}$} & \multicolumn{4}{|c|}{ Detection of HIV antibodies by First Response HIV 1-2.O } & \multicolumn{4}{|c|}{ Detection of HIV antibodies by HIV TRI-DOT } \\
\hline & HIV-1 & HIV-2 & HIV-1/HIV-2 & Negative & HIV-1 & HIV-2 & HIV-1/HIV-2 & Negative \\
\hline Positive (n = 79) & 70 & 2 & 7 & 0 & 75 & 2 & 2 & $\mathrm{ND}^{\mathrm{a}}$ \\
\hline Negative $(\mathrm{n}=55)$ & 0 & 0 & 0 & 55 & ND & ND & ND & ND \\
\hline
\end{tabular}

${ }^{\text {a }}$ Specimens found negative for HIV in First Response HIV card test 1-2.O were not subjected to HIV TRI-DOT.

ND, not done.

double-ELISA does not differentiate between HIV-1 and HIV-2, all the HIV-2 results were analyzed separately (Table 2).

The results analyzed for the detection of HIV-2 are summarized in Table 3. In total, there were 17 HIV-2positive specimens obtained from this study, in which seven specimens (specimens 1-7) were found to be positive for HIV-1 and 2 in screening and confirmatory assays. Another five specimens (specimens 13-17) were positive for HIV-1 and -2 by First Response HIV card test 1-2.O and positive for HIV-1 only by HIV TRIDOT; these were found to be indeterminate with HIV-2 Western blot. Specimens 8 and 9 were negative for HIV1 and positive for HIV-2 by both of the screening assays; these two specimens were confirmed to be positive for HIV2 by Western blot. However, one of these specimens was indeterminate for HIV-1 (presence of gp160 band). Specimens 10 and 11 were positive for HIV-1 by both the assays and positive for HIV-2 by the First Response HIV card test 1-2.O only, although these two were confirmed positive for HIV-2 by Western blot. Specimen 12 was correctly detected as HIV-2 by both the rapid assays and was negative for HIV-1 by TRI-DOT (which was indeterminate by HIV-1 Western blot).

\section{Evaluation of Reproducibility}

The First Response HIV card test 1-2.O presented a reproducibility index of $100 \%$ for a HIV-positive specimen when it was repeated 10 times. Also, there were no discrepancies found between the two different personnel.

\section{DISCUSSION}

The First Response HIV card test 1-2.O assay was able to pick up all HIV-positive and -negative specimens correctly and the sensitivity, specificity, NPV, PPV, and efficiency were $100 \%$ in detection of antibodies to HIV1 in serum and plasma specimens. The repeatability and interpersonal variation was also good with this assay. We are using it as the primary assay in our HIV screening algorithm. However, if any specimen is falsepositive in this assay, it may give a negative result when retested with another assay, since false-positive reactions are often assay-specific. Our second assay (HIV TRIDOT) was more specific from published evidence for HIV-1 (5,15); we are using it because any supportive assay must be more specific, it must also have sensitivity similar to that of the primary assay (28). In our serial algorithm the negative result with the first assay is considered negative. Also, giving counseling for HIV rescreening after 1 month and to protect him/her from any new exposures is the norm at our clinic.

Screening assays should primarily produce concordant results $(17,18,19)$ whereas Western blot should be used as the test for true determination of results $(18,20)$. Even though there have been only less numbers of HIV-2 infections identified in India so far, it has been common practice in diagnostic laboratories, and compulsory for transfusion services for several years, to use combined antibody screening assays for both HIV-1 and HIV-2 to detect potential cases. It may be of concern to ascertain that the sensitivity and specificity for the detection of HIV-1 antibodies are not compromised by the addition of HIV-2 antigens and vice versa. There were seven specimens found HIV-2-negative in HIV TRI-DOT, but they were HIV-2-positive using the First Response HIV card test 1-2.O, out of which two were found positive for HIV-2 by Western Blot. In all the seven specimens, there was no gp36 band found. That could be the possible reason why HIV TRI-DOT missed them for HIV-2. The false negativity of HIV-2 with HIV TRI-DOT BIOMED must be severely taken into account because: 1) there is a high degree of chance to miss HIV-2 infection in any patient who is infected with HIV-2 alone or combined with HIV-1; 2) the assay is widely used in this country $(5,15)$; and 3 ) treatment regimens are also specific to HIV subtypes $(21,22,23)$. Out of these seven specimens, five were HIV-2-indeterminate, all had p26 band, and two specimens had gp105/ 125 in addition to $\mathrm{p} 26$. There may be HIV-2 seroconversion with these patients but at the same time HIV-2 false indeterminate results were often possible due to other clinical conditions $(20,24,25)$. However, more prospective studies are needed to analyze the HIV-2 Western Blot indeterminate status. 
The First Response HIV card test 1-2.O has picked up an HIV-1-indeterminate specimen (specimen number 12 in Table 3); this information must be noted in terms of high sensitivity $(100 \%)$ with the First Response HIV card test 1-2.O assay for HIV-1 and HIV-2. This could not be a limitation because high sensitivity is preferred in screening assays; any false positivity will be ruled out when it is confirmed with supportive screening assays. Whenever discrepancies are found they must be checked with a third assay (26) or Western blot (applies to both HIV-1 and -2). A limitation in our study was that we lack HIV deoxyribonucleic acid (DNA) polymerase chain reaction (PCR) results, due to its high cost, to rule out HIV infection in Western blot indeterminate specimens. Also DNA PCR results would have been useful to rule out the cross-reaction between HIV-1 and HIV-2 specimens. However, parallel testing might improve the sensitivity of the HIV testing algorithm (27-30) but little expensive.

The World Health Organization (WHO) has addressed the issues of increasing in-country capabilities for infectious disease diagnosis $(21,26)$, particularly in the case of HIV infection, and incorporating the use of rapid diagnostic tests into standard laboratory formats and point-of-care facilities (9). For example, the strategy for HIV testing recommends sequential testing of specimens by either ELISAs or rapid assays with different antigenic bases. Specimens are screened by one method, and reactive specimens can then be tested by a second assay. In India, ELISA tests are available in cities, but in smaller towns and rural areas, facilities for ELISA are unavailable. With the availability of commercial rapid tests, it has become possible to costeffectively screen smaller numbers of specimens without a huge initial input for the laboratory. Especially with the First Response HIV card test 1-2.O assay; it is possible to store the test kit at room temperature up to $30^{\circ} \mathrm{C}$, which can eliminate the use of refrigerators, and the assay will be useful for HIV screening in field studies. Thus, screening of specimens by the rapid First Response HIV card test 1-2.O could serve as first-line diagnostic support with follow-up by the secondary method only for specimens that appear to be positive upon initial testing. As the assay is completed within $15 \mathrm{~min}$, it is possible to give rapid and reliable results immediately. Giving instant negative results to the patients can alleviate fear and anxiety, or immediate counseling and treatment options may be undertaken in case of positive results. Either way, patients are immediately aware of their potential disease status.

Also, many patients in developing countries cannot afford to go for costlier diagnostic methods like Western blot and PCR assays. Hence, a rapid assay can be used to give accurate and reliable results with affordable cost.
A careful choice of rapid HIV detection assay also must be made by any laboratory to minimize possible errors. If a test of inferior quality is chosen for testing the highrisk population, following up on false results will consume time and money. False-positive results could cause considerable unnecessary apprehension in patients when used diagnostically, and they could result in the unnecessary waste of valuable blood in blood banks. The damage caused by false-negative test results is also serious. A person who is falsely informed that he or she is negative and then not properly followed could readily spread the virus through sexual contacts in the following months. The possibility of transfusing blood after such a false-negative test also underlines the need for highquality, sensitive HIV screening assays.

As per the WHO guidelines, specimen positive in two different assays can be declared for HIV infection even without Western blot results (26). Even though Western blot is a confirmatory test $(4,32,33)$, the combination of two or more antibody screening assays, which use different antigenic bases, may be more sensitive and specific than Western blot (11,18,32-35). Also, the use of Western blot, particularly when stringent criteria are applied, is problematic during the early phases of HIV infection, when the specimen will be reactive in ELISA and negative or indeterminate in Western blot (24); this is because of the time gap that is required for developing various antibodies specific to different HIV-1 antigens. It is also noted that the sera of up to $40 \%$ of uninfected persons give indeterminate Western blot results $(19,24,32,33)$. As far as PCR is concerned it is an effective diagnostic tool to identify the presence of the HIV genome in the window period (36), but it is not needed for HIV screening and is also not appreciated in developing countries due to its higher cost.

The First Response HIV card test 1-2.O has several advantages for the consideration of the kit in resourcelimited settings, such as, low cost (at U.S. $\$ 0.70$, it is less than half the price as compared to other commercial assays), needs only $10 \mu \mathrm{L}$ of specimen, simple to perform and involves only two steps, short turnaround time requires only $20 \mathrm{~min}$ to finish the assay, the kit can be stored even up to $30^{\circ} \mathrm{C}$, ability to differentiate HIV-1 and HIV-2, and use of whole blood specimens. There are no prior publications found using or referring to this assay; however, evaluation reports from different regulatory bodies and government/autonomous institutions are available to witness the high efficiency of the First Response HIV card test 1-2.O.

The First Response HIV card test 1-2.O can also be interpreted easily, and no specialized equipment or ancillary reagents were required to perform the assay. Because of these features, the First Response HIV card test 1-2.O could provide a valuable tool to rapidly screen 


\section{4 lqbal et al.}

patient specimens at point-of-care facilities, reference laboratories, prenatal clinics, for the evaluation of patient-derived specimens when healthcare workers are accidentally exposed (i.e., whether to begin postexposure prophylaxis), and also in emergency rooms located in regions where the laboratory infrastructure is neither present nor well-outfitted $(7,9,10)$. Hence, this test kit could be suitable for initial screening in the HIV testing algorithm in resource-limited settings.

\section{ACKNOWLEDGMENTS}

We thank our clinic and laboratory staff for their assistance in completing the work.

\section{REFERENCES}

1. Simoes E, Babu A, John PG, et al. Evidence for HTLV-III infection in prostitutes in Tamil Nadu (India). Indian J Med Res 1987;85:335-338.

2. Joint United Nations programme on HIV/AIDS (UNAIDS). 2.5 million people in India living with HIV, according to new estimates. 2007. Press release. [Online] http://www.unaids.org/en/ MediaCentre/PressMaterials/FeatureStory/20070704_India_new_ data.asp

3. Solomon S, Kumarasamy N, Ganesh AK, Amalraj RE. Prevalence and risk factors of HIV-1 and HIV-2 infection in urban and rural areas in Tamil Nadu, India. Int $\mathbf{J}$ Std AIDS 1998;9:98-103.

4. Syed Iqbal H, Suniti Solomon, Murugavel KG, Sunil Suhas Solomon, Balakrishnan P. Evaluation and diagnostic usefulness of domestic and imported enzyme-linked immunosorbent assays for detection of human immunodeficiency virus type 1 antibody in India. Clin Diagn Lab Immunol 2005;12:1425-1428.

5. Rajesh K, Ramalingam S, Pradeepkumar S, Damodharan K, Sridharan G. Hospital-based evaluation of two rapid human immunodeficiency virus antibody screening tests. J Clin Microbiol 2000;38:3445-3447.

6. World Health Organization. The importance of simple/rapid assays in HIV testing. WHO/UNAIDS recommendations. Wkly Epidemiol Rec 1998;42:321-326.

7. Kannagai R, Prabu K, Vincent AA, Vijayakumar TS, Sridharan G. Performance evaluation of four different kits available in the Indian market, for the rapid detection of HIV antibody. Indian J Med Microbiol 2003;21:193-195.

8. Aidoo S, Ampofo WK, Brandful JAM, et al. Suitability of a rapid immunochromatographic test for detection of antibodies to human immunodeficiency virus in Ghana, West Africa. J Clin Microbiol 2001;39:2572-2575.

9. Palmer CJ, Dubon JM, Koenig E, et al. Field evaluation of the determine rapid human immunodeficiency virus diagnostic test in Honduras and the Dominican Republic. J Clin Microbiol 1999;37:3698-3700.

10. Rodrigo-Rodrigues R, Da Silva Pinto Neto LF, Carla BC, Valeria PC, Reynaldo D. Performance characteristic of a rapid new immunochromatographic test for detection of antibodies to human immunodeficiency virus. Clin Diagn Lab Immunol 2003;10:303-307.

11. Kagulire SC, Stamper PD, Opendi P, et al. Performance of two commercial immunochromatographic assays for rapid detection of antibodies specific to human immunodeficiency virus types 1 and 2 in serum and urine samples in a rural community-based research setting (Rakai, Uganda). Clin Vaccine Immunol 2007;14:738.

12. Vijayakumar TS, David S, Selvaraj K, Viswanathan T, Kannangai R, Sridharan G. Performance of a rapid immunochromatographic screening test for detection of antibodies to human immunodeficiency virus type 1 (HIV-1) and HIV-2: experience at a tertiary care hospital in South India. J Clin Microbiol. 2005;43:4194-4196.

13. Solomon S, Kouyoumdjian FG, Cecelia AJ, James R, James L, Kumarasamy N. Why are people getting tested? Self-reported reasons for seeking voluntary counseling and testing at a clinic in Chennai, India. AIDS Behav 2006;10:415-420.

14. Gerald SJ, George R. AIDS testing, methodology and management issues. New York: Spring Verlag; 1992. p 66.

15. Sudha T, Teja VD, Gopal M, Rajesh M, Lakshmi V. Comparative evaluation of TRI-DOT Rapid HIV test with fourth-generation ELISA for the detection of human immunodeficiency virus. Clin Microbiol Infect 2005;11:850-852.

16. Thakral B, Saluja K, Sharma RR, Marwaha. Algorithm for recall of HIV reactive Indian blood donors by sequential immunoassays enables selective donor referral for counseling. J Postgrad Med 2006;52:106-110.

17. Lin HJ, Myers LE, Yen-Lieberman B, et al. Multicenter evaluation of quantification methods for plasma human immunodeficiency virus type 1 RNA. J Infect Dis 1994;170:553-562.

18. Matter L, Germann D. Detection of human immunodeficiency virus (HIV) type 1 antibodies by new automated microparticle enzyme immunoassay for HIV types 1 and 2. J Clin Microbiol 1995;33:2338-2341.

19. Pyra H, Boni J, Schupbach J. Ultrasensitive retrovirus detection by a reverse transcriptase assay based on product enhancement. Proc Natl Acad Sci USA 1994;91:1544-1548.

20. Cedric M, Pontiano K, Amato O, James AG. Human immunodeficiency virus type 1 Western blot: revised diagnostic criteria with fewer indeterminate results for epidemiological studies in Africa. Int J Epidemiol 2002;31:985-990.

21. Christopher M, Geoffrey E, Stephen P, et al. Highly active antiretroviral therapy and viral response in HIV Type 2 infection. Clin Infect Dis 2004;38:1771-1779.

22. Jallow S, Kaye S, Alabi A, et al. Virological and immunological response to Combivir and emergence of drug resistance mutations in a cohort of HIV-2 patients in The Gambia. AIDS 2006;20:1455-1458.

23. Rodes B, Holguin A, Soriano V, Dourana M, Mansinho K, Antunes F. Emergence of drug resistance mutations in human immunodeficiency virus type 2-infected subjects undergoing antiretroviral therapy. J Clin Microbiol 2000;38:1370-1374.

24. Ming Guan. Frequency, causes, and new challenges of indeterminate results in Western blot confirmatory testing for antibodies to human immunodeficiency virus. Clin Vaccine Immunol 2007; 16:649.

25. Rae FM, Healey DS, Best SJ, Dax EM. Characterization of HIV-2 Western blot reactivity. Int Conf AIDS; 1993. Abstract PO-A310759 .

26. World Health Organization and Joint United Nations Programme on HIV/AIDS. Guidelines for using HIV testing technologies in surveillance guidelines for using HIV testing technologies in surveillance: selection, evaluation, and implementation. WHO/ CDS/CSR/EDC/2001.16, UNAIDS/01.22E. 2001. [Online] http:// www.who.int/hiv/pub/surveillance/en/guidelinesforUsingHIVTestingTechs_E.pdf.

27. Granade TC, Parekh BS, Tih PM, et al. Evaluation of rapid prenatal human immunodeficiency virus testing in rural Cameroon. Clin Diagn Lab Immunol 2005; 12:855-860. 
28. Wright RJ, Stringer JS. Rapid testing strategies for HIV-1 serodiagnosis in high-prevalence African settings. Am J Prev Med 2004;27:42-48.

29. Meless H, Tegbaru B, Messele T, et al. Evaluation of rapid assays for screening and confirming HIV-1 infection in Ethiopia. Ethiop Med J 2002;40:27-36.

30. Singer DE, Kiwanuka N, Serwadda D, et al. Use of stored serum from Uganda for development and evaluation of a human immunodeficiency virus type 1 testing algorithm involving multiple rapid immunoassays. J Clin Microbiol 2005;43: $5312-5315$.

31. World Health Organization and Joint United Nations Programme on HIV/AIDS. Guidance on provider-initiated HIV testing and counseling in health facilities. 2007. [Online] http://whqlibdoc.who.int/publications/2007/9789241595568_eng.pdf.
32. Genesca J, Jett BW, Epstein JS, et al. What do Western blot indeterminate patterns for human immunodeficiency virus mean in EIA-negative blood donors? Lancet 1989;2:1023-1025.

33. Midthun K, Garrison L, Clements ML, et al. Frequency of indeterminate Western blot tests in healthy adults at low risk for human immunodeficiency virus infection. J Infect Dis 1990;162: 1379-1382.

34. Mortimer PP. The fallibility of HIV Western blot. Lancet 1991;337:286-287.

35. Sato PA, Maskill WJ, Tamashiro H, Heymann DL. Strategies for laboratory HIV testing: an examination of alternative approaches not requiring Western blot. Bull World Health Organ 1994; 72:129-134.

36. Piquet $\mathrm{Y}$, Ivanovic Z, Laperche S, et al. Nucleic acid amplification testing detection of an HIV-1 infection in a blood donor during the preseroconversion window period. Transfus Med 2007;17: $147-148$. 